\title{
The Role of Endothelin and Endothelin Receptor Subtypes in Regulation of Fetal Pulmonary Vascular Tone
}

\author{
JACKSON WONG, JEFFREY R. FINEMAN, AND MICHAEL A. HEYMANN \\ Department of Pediatrics and the Cardiovascular Research Institute, University of California. San Francisco, \\ San Francisco, California 94143-0544
}

\begin{abstract}
The physiologic role of endothelin-1 (ET-1) and its receptors in regulating fetal pulmonary vascular tone is unknown. We therefore investigated the role of ET. 1 and its receptors in the regulation of fetal pulmonary vascular tone using $B Q 123$ (an ET, receptor antagonist) and 4 Ala ET-1 (an $E_{b}$ receptor agonist). In six fetal sheep in utero, we found that injections of ET-1 (250 $\mathrm{ng} /$ kg fetal weight) into the left pulmonary artery increased left pulmonary blood flow $(21.0 \pm 17.5$ to $74.7 \pm 32.9 \mathrm{~mL} /$ $\mathrm{kg} / \mathrm{min}, p<0.05)$ and decreased left pulmonary vascular resistance $(6.02 \pm 7.00$ to $0.84 \pm 0.48 \mathrm{~mm} \mathrm{Hg} / \mathrm{kg} / \mathrm{min} / \mathrm{mL}$, $p<0.05)$. BQ $123(5 \mathrm{mg})$ increased pulmonary blood flow $(24.6 \pm 28.7$ to $47.7 \pm 27.4 \mathrm{~mL} / \mathrm{kg} / \mathrm{min}, p<0.05)$ and decreased pulmonary vascular resistance $(8.84 \pm 10.32$ to $1.43 \pm 0.80 \mathrm{~mm} \mathrm{Hg} / \mathrm{kg} / \mathrm{min} / \mathrm{mL}, p<0.05) ; 4$ Ala ET-1 $(1725 \mathrm{ng} / \mathrm{kg})$ markedly increased pulmonary blood flow $(8.6 \pm 6.8$ to $69.4 \pm 23.1 \mathrm{~mL} / \mathrm{kg} / \mathrm{min}, p<0.05)$ and decreased pulmonary vascular resistance $(12.02 \pm 10.2$ to $0.78 \pm 0.44 \mathrm{~mm} \mathrm{Hg} / \mathrm{kg} / \mathrm{min} / \mathrm{mL}, p<0.05$ ). The absolute increase in pulmonary blood flow produced by ET-1 was attenuated by glibenclamide (an ATP-dependent potassium channel blocker) (flow increase of $73.4 \pm 34.1$ versus 49.3 $\pm 16.8 \mathrm{~mL} / \mathrm{kg} / \mathrm{min}, p<0.05$ ). This study demonstrates that ET, receptor activation has a small role in maintaining basal fetal pulmonary vascular tone, and that specific ET receptor activation produces marked pulmonary vasodilation. The increase in pulmonary flow produced by ET-1 in fetuses is partly mediated by ATP-dependent potassium channels. (Pediatr Res 35: 664-670, 1994)
\end{abstract}

\section{Abbreviations}

ET-1, endothelin-1

$\mathrm{ET}_{\text {a, }}$ endothelin receptor subtype a $\mathbf{E T}_{\text {b, }}$ endothelin receptor subtype b EDNO, endothelium-derived nitric oxide

Although exogenous ET-1 is a potent pulmonary vasodilator in the fetal and neonatal circulations $(1-4)$, the physiologic role of ET-1, and of its receptors, in regulating fetal pulmonary vascular tone is unknown. The hemodynamic effects of ET-1 are mediated by at least two distinctive receptor types, $\mathrm{ET}_{\mathrm{a}}$ and $\mathrm{ET}_{\mathrm{b}}$ receptors. The $\mathrm{ET}_{\mathrm{a}}$ receptors, located on vascular smooth muscle cells, are responsible for the vasoconstrictor effects of ET-1 (5-

Received August 19, 1993; accepted February 7, 1994

Correspondence and reprint requests: Michael Heymann, M.D., Box 0544, HSE 1403, University of California, San Francisco, San Francisco, CA 94143-0544.

Supported by Grants HL 40473 and HL 35518 from the National Heart, Lung and Blood Institute and by the University of California, San Francisco Committee on Research.
8). There are two subtypes of $\mathrm{ET}_{\mathrm{b}}$ receptors, $\mathrm{ET}_{\mathrm{b}}$ vasodilator receptors and $\mathrm{ET}_{b}$ vasoconstrictor receptors $(9-14)$. The $\mathrm{ET}_{\mathrm{b}}$ vasodilator receptors, located on endothelial cells, are responsible for the vasodilation produced by ET-1 $(10,11,14)$. Activation of $\mathrm{ET}_{\mathrm{b}}$ receptors seems to produce pulmonary vasodilation by releasing EDNO, as well as by activating ATP-dependent potassium channels $(3,4,15-17)$. In contrast, $\mathrm{ET}_{\mathrm{b}}$ vasoconstrictor receptors are thought to be located on the vascular smooth muscle, and their mechanism of action is unknown (12-14).

Recently, potent, selective ET-1 receptor subtype antagonists and agonists have been developed. BQ 123 [Cyclo (D-Asp-L-ProD-Val-L-Leu-D-Trp), Peptides International, Louisville, KY], a cyclic pentapeptide, is a potent $\mathrm{ET}_{\mathrm{a}}$ receptor antagonist (6-8). In contrast, 4 Ala ET-1 (Ala ${ }^{13.11 .15}$ ET-1, Parke-Davis, Ann Arbor, $\mathrm{MI})$ is a potent $\mathrm{ET}_{\mathrm{b}}$ receptor agonist $(10,11,18)$. We have previously shown that $\mathrm{BQ} 123$ is a selective $\mathrm{ET}_{\mathrm{a}}$ antagonist in newborn lambs and inhibits ET-1-induced pulmonary vasoconstriction (8). In contrast to BQ 123, 4 Ala ET-1 is a selective ET agonist that induces pulmonary vasodilation during U44619induced pulmonary hypertension (18).

This study had two main objectives. The first was to investigate the role of ET-1 and its receptors in the regulation of pulmonary vascular tone in near-term, chronically instrumented fetal sheep in utero by studying the effects of a selective ET-1 receptor antagonist and agonist. The second objective was to investigate the mechanism of the ET-1 effect on the pulmonary circulation. For the first objective, we studied the effects of injections of ET1 and 4 Ala ET-1 into the left pulmonary artery and inferior vena cava and infusions of BQ 123 into the left pulmonary artery on fetal pulmonary vascular tone. For the second objective, we compared the hemodynamic effects of exogenous ET-1 before and during the infusion of glibenclamide (an ATP-dependent potassium channel blocker).

\section{MATERIALS AND METHODS}

Surgical preparation. Fetal surgery was performed as previously described (19). Briefly, a total of six Western fetal sheep were studied at $135.8 \pm 6.1 \mathrm{~d}$ gestational age (term $145 \mathrm{~d}$ ). The ewe was anesthetized with an epidural injection of $4 \mathrm{~mL}$ of $1 \%$ tetracaine hydrochloride. Polyvinyl catheters were inserted into the maternal pedal vein and artery after local infiltration with $2 \%$ lidocaine hydrochloride.

With use of aseptic techniques, the uterus was exposed through a midline incision. Through a small uterine incision the hind limb was exposed, and polyvinyl catheters were inserted into the fetal pedal vein and artery and their tips advanced to the descending aorta and inferior vena cava, respectively. Through a second uterine incision, a left lateral thoracotomy was performed in the third intercostal space. Succinylcholine hydrochloride (3 to 5 $\mathrm{mg}$ ) was administered i.v. to prevent fetal breathing movements. Polyvinyl catheters were then inserted into the internal thoracic 
artery and vein and their tips advanced to the ascending aorta and right atrium, respectively. The pericardium was incised along the main pulmonary trunk. ET-1 may constrict the ductus arteriosus and thereby influence pulmonary blood flow $(20,21)$; therefore, to prevent ductus vasoreactivity during subsequent pharmacologic studies, the ductus arteriosus was visualized and the adventitia infiltrated with $10 \%$ formalin colored with a few drops of sterile methylene blue solution. Three Teflon cannulas attached to polyvinyl catheters were then inserted, one into the main pulmonary trunk, one directly into the left pulmonary artery (tip pointing toward the lung, positioned about $1 \mathrm{~cm}$ beyond the main pulmonary artery bifurcation), and one into the left atrium. A 4-mm ultrasonic flow transducer (Transonic Systems, Inc., Ithaca, NY) was placed around the left pulmonary artery to measure left pulmonary arterial blood flow. The thoracotomy incision was closed in layers. Warm saline was infused to replace the lost amniotic fluid, and the uterine incision was closed. A 12 French chest tube was placed in the amniotic cavity. The catheters were filled with heparin sodium, plugged, and brought to the skin along with the transducer cable, where they were protected in a pouch secured to the ewe's flank. After recovery from anesthesia, the ewe was returned to the cage. At least $2 \mathrm{~d}$ were allowed for recovery. Daily, 1 million $U$ of penicillin $\mathrm{G}$ procaine and $100 \mathrm{mg}$ of gentamicin suspension were administered to the ewe and also into the amniotic cavity. All protocols were approved by the Committee on Animal Research of the University of California, San Francisco.

Drug preparation. ET-1 (0.5 mg) (Peptides International, Inc.) was resuspended in $10 \mathrm{~mL}$ of sterile water and stored at $-20^{\circ} \mathrm{C}$. BQ $123(5 \mathrm{mg})$ (Peptides International Inc.) was resuspended in $1 \mathrm{M}$ sodium bicarbonate to a final concentration of $1 \mathrm{mg} / \mathrm{mL}$. The 4 Ala ET-1 (Ala ${ }^{1,3,11,15}$ ET-1, Parke-Davis) was resuspended in $2 \%$ DMSO-sterile water. Immediately before administration, each dose of ET-1 and 4 Ala ET- 1 was measured and diluted to $1 \mathrm{~mL}$ with $0.9 \%$ saline. Cromakalim (Smith Kline Beecham Pharmaceuticals, Surrey, England) was dissolved in $0.9 \%$ saline. Glibenclamide (Glybenclamide, Sigma Chemical Co., St. Louis, $\mathrm{MO}$ ) was dissolved in sterile water and titrated to $\mathrm{pH} 12.0$ with the addition of $1 \mathrm{~N} \mathrm{NaOH}$. All solutions were prepared on the day of the study and kept on ice until administered.

Experimental protocol. In six chronically instrumented fetal sheep, we studied the hemodynamic effects of injections of ET1 and 4 Ala ET-1 into the left pulmonary artery and inferior vena cava and of infusions of BQ 123 into the left pulmonary artery. The route of administration and the drug for administration were randomly selected. Pulmonary artery and inferior vena cava injections were studied to assess possible differential hemodynamic effects secondary to the route of administration. In five of these six fetal sheep, after allowing a 24 -h recovery period, we studied the hemodynamic effects of injections of ET-1 into the left pulmonary artery before and during glibenclamide (an ATPdependent potassium channel blocker) infusion. The doses of ET-1, 4 Ala ET-1, cromakalim (an ATP-dependent potassium channel activator), and glibenclamide were based on the estimated weight of the fetus at time of surgery $(3.17 \pm 0.41 \mathrm{~kg})$; the actual weight at autopsy was $2.75 \pm 0.48 \mathrm{~kg}$.

ET-I and 4 Ala ET-I injections. The fetal sheep was studied with the ewe standing quietly in a study cart with free access to food and water. Succinylcholine hydrochloride $(20 \mathrm{mg})$ was given for muscle relaxation to prevent fetal movements. Baseline measurements of the hemodynamic variables (pulmonary arterial blood pressure, left pulmonary arterial blood flow, systemic arterial blood pressure, heart rate, left and right atrial pressures, and amniotic fluid pressure) and systemic arterial blood gases and $\mathrm{pH}$ were measured. ET- $1(250 \mathrm{ng} / \mathrm{kg}), 4$ Ala ET-1 $(1725 \mathrm{ng} /$ $\mathrm{kg}$ ), or their vehicles, $0.9 \%$ saline or $2 \%$ DMSO, were then injected into the left pulmonary artery or inferior vena cava in random order. Previously, we found that these doses, administered in bolus injections, produced reproducible, potent, yet short-term pulmonary vasodilation in newborn lambs $(4,18)$.
The short duration of effect allowed repeated testing of these difficult preparations. Each agent was injected over $10 \mathrm{~s}$, followed by a $2-\mathrm{mL}$ flush of $0.9 \%$ saline. The hemodynamic variables were monitored continuously and measured at the point of maximum change in left pulmonary arterial blood flow (ET-1 and 4 Ala ET-1). Systemic arterial blood gases and $\mathrm{pH}$ were measured 15 min after injections of ET-1 or 4 Ala ET-1 into the left pulmonary artery. At least $60 \mathrm{~min}$ were allowed between each injection for all hemodynamic variables to return to preinjection values. All measurements were then repeated, and another agent was given.

Infusions of $B Q 123$ into the left pulmonary artery. Baseline measurements of the hemodynamic variables and systemic arterial blood gases and $\mathrm{pH}$ were measured. BQ $123(5 \mathrm{mg})$ or sodium bicarbonate (drug vehicle) $(5 \mathrm{mEq})$ in random order was then infused into the left pulmonary artery over $5 \mathrm{~min}$. The hemodynamic variables were measured 5 and $10 \mathrm{~min}$ after the start of the infusion, and systemic arterial blood gases and $\mathrm{pH}$ were measured $5 \mathrm{~min}$ after the start of the infusion. Previously, we found that this dose of BQ 123 inhibited pulmonary vasoconstriction induced by ET-1 in lambs (8).

ET-1 injections during glibenclamide infusion. After a 24-h recovery period, five of the six fetal sheep could be studied again. Baseline measurements of the hemodynamic variables, systemic arterial blood gases, and $\mathrm{pH}$ were made. Then ET-1 $(250 \mathrm{ng} / \mathrm{kg})$ or cromakalim $(50 \mu \mathrm{g} / \mathrm{kg}$; a potassium channel activator) was injected in random order into the left pulmonary artery. All variables were measured at the point of maximal left pulmonary arterial blood flow effect. Systemic arterial blood gases and $\mathrm{pH}$ were measured $15 \mathrm{~min}$ after the injection of the agent. At least $60 \mathrm{~min}$ were allowed between injections for all variables to return to preinjection values. One hour after the second injection, when all variables had returned to baseline, glibenclamide $(0.7 \mathrm{mg} / \mathrm{kg} /$ min), an ATP-gated potassium channel blocker, was infused into the left pulmonary artery. After $15 \mathrm{~min}$, while the glibenclamide infusion continued, all variables were again measured to evaluate the effects of glibenclamide alone on these variables. Thereafter, the injections of ET-1 or cromakalim were repeated (in the presence of glibenclamide) and all variables were again measured as described above. Responses to the injections of ET-1 or cromakalim during glibenclamide infusion were evaluated by comparing the measurements obtained at maximal effect with those obtained immediately before the injection of ET-1 or cromakalim. Previous studies from our laboratories (19) have shown that in these volumes the i.v. infusion of distilled water ( $\mathrm{pH}$ 12) did not change the hemodynamic variables or the responses to ET-1 or cromakalim.

At the end of the study, the ewes were given a lethal dose of pentobarbital sodium, then the fetus was removed. Catheter placement was confirmed at autopsy, and the fetus was weighed.

Measurements. Pulmonary and systemic arterial blood pressures and right and left atrial pressures were measured by Statham P23Db pressure transducers (Statham Instruments, Hato Rey, Puerto Rico). Mean pressures were obtained by electrical integration. Heart rate was measured by a cardiotachometer triggered from the phasic systemic arterial pressure pulse wave. Left pulmonary arterial blood flow was measured by a transit time flow meter (Transonic Systems, Inc.). All hemodynamic variables were recorded continuously on a Gould multichannel electrostatic recorder (Gould Inc., Cleveland, $\mathrm{OH}$ ). Systemic arterial (descending aortic) blood gases and $\mathrm{pH}$ were measured on a Corning $158 \mathrm{pH} /$ blood gas analyzer (Corning Medical and Scientific, Medfield, MA). All fetal pressures were corrected to amniotic fluid pressure as a zero reference level. Left pulmonary arterial vascular resistance was calculated as follows: (mean pulmonary arterial blood pressure - mean left atrial pressure) $\div$ (left pulmonary arterial blood flow $/ \mathrm{kg}$ of fetal weight).

Statistical analysis. Means \pm SD were calculated for the hemodynamic variables, systemic arterial blood gases, and $\mathrm{pH}$ during all experimental conditions. The effects of each vasoactive agent 
(ET-1, BQ 123, 4 Ala ET-1, sodium bicarbonate, cromakalim, and glibenclamide) on these variables were compared with their previous steady state (baseline) condition by the paired $t$ test.

Changes in left pulmonary arterial blood flow and left pulmonary vascular resistance were compared by the Wilcoxon Signed Rank test because of their wide SD. The absolute changes in left pulmonary vascular resistance and left pulmonary arterial blood flow and the percent change in mean pulmonary arterial blood pressure produced by left pulmonary artery injections of ET- 1 and 4 Ala ET- 1 were compared with the respective changes produced by inferior vena cava injections of ET-1 and 4 Ala ET1. Similarly, changes in response to injections of ET-1 or cromakalim before or during glibenclamide infusion were assessed by the Wilcoxon Signed Rank test. Baseline measurements before each intervention were compared by analysis of variance for repeated measures and were not different. For all evaluations, $p<0.05$ was considered statistically significant.

\section{RESULTS}

Fetal baseline arterial blood gases and $\mathrm{pH}$ were measured before starting each study and were within the normal range for the laboratory (Table 1).

ET-1 and 4 Ala ET-1 injections. Injections of ET-1 into the left pulmonary artery increased left pulmonary arterial blood flow and decreased left pulmonary vascular resistance (Table 1). Mean pulmonary and systemic arterial blood pressures were unchanged. Injections of ET-1 into the inferior vena cava increased left pulmonary arterial blood flow but did not significantly change left pulmonary vascular resistance or mean pulmonary and systemic arterial blood pressures (Fig. 1, Table 1). Injections of ET-1 into the left pulmonary artery produced a greater decrease in left pulmonary vascular resistance than injections into the inferior vena cava $(5.17 \pm 7.12$ versus $1.26 \pm 2.14$ $\mathrm{mm} \mathrm{Hg} / \mathrm{mL} / \mathrm{kg} / \mathrm{min}, p<0.05$ ). The increase in left pulmonary arterial blood flow produced by injections into both the left pulmonary artery and the inferior vena cava started immediately, and the maximum flow increase occurred within $10 \mathrm{~s}$ and lasted for $254.2 \pm 109.0$ and $224.0 \pm 67.3 \mathrm{~s}$, respectively.

Injections of 4 Ala ET-1 into the left pulmonary artery and the inferior vena cava produced similar increases in left pulmonary arterial blood flow and similar decreases in left pulmonary vascular resistance. Mean pulmonary and systemic arterial blood pressures were unchanged. The increase in left pulmonary arterial blood flow produced by injections into the left pulmonary artery and the inferior vena cava lasted 120.0 \pm 73.8 and $124.0 \pm 43.4$ s, respectively.

Injections of 4 Ala ET-1 into the left pulmonary artery produced a greater increase in left pulmonary arterial blood flow than did injections of ET-1 into the left pulmonary artery $(60.8$ \pm 28.6 versus $53.7 \pm 34.5 \mathrm{~kg} / \mathrm{mL} / \mathrm{min}, p<0.05)$. The injections of $0.9 \%$ saline and $2 \%$ DMSO as controls had no hemodynamic effects.

Infusions of $B Q 123$ into the left pulmonary artery. The infusion of BQ 123 into the left pulmonary artery increased left pulmonary arterial blood flow and decreased left pulmonary vascular resistance at both 5 and $10 \mathrm{~min}$ after the start of the infusion (Fig. 2, Table 2). Mean pulmonary and systemic arterial blood pressures were unchanged. The infusion of sodium bicarbonate into the left pulmonary artery did not change any of the hemodynamic variables.

ET-I injections before and during glibenclamide infusion. In the five animals studied on the second day, before the infusion of glibenclamide, ET-1 increased left pulmonary arterial blood flow and decreased left pulmonary vascular resistance as well as mean pulmonary and systemic arterial blood pressures (Fig. 3, Table 3). Similarly, before the infusion of glibenclamide, cromakalim increased left pulmonary arterial blood flow and decreased left pulmonary vascular resistance and mean pulmonary arterial blood pressure. Systemic arterial blood pressure was

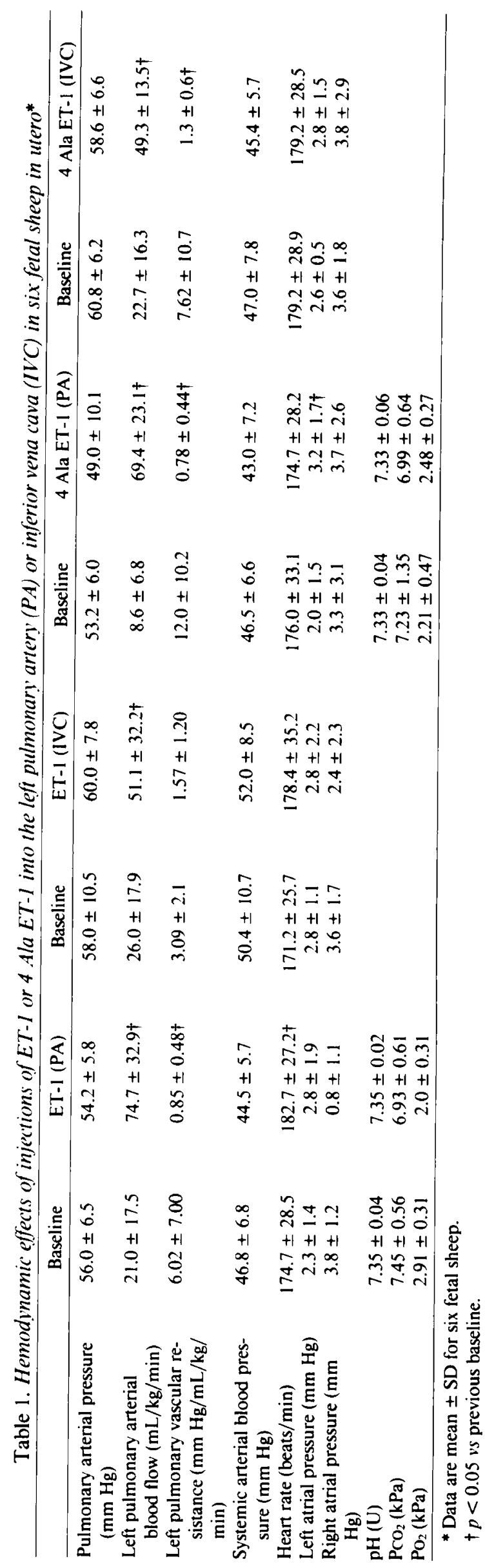




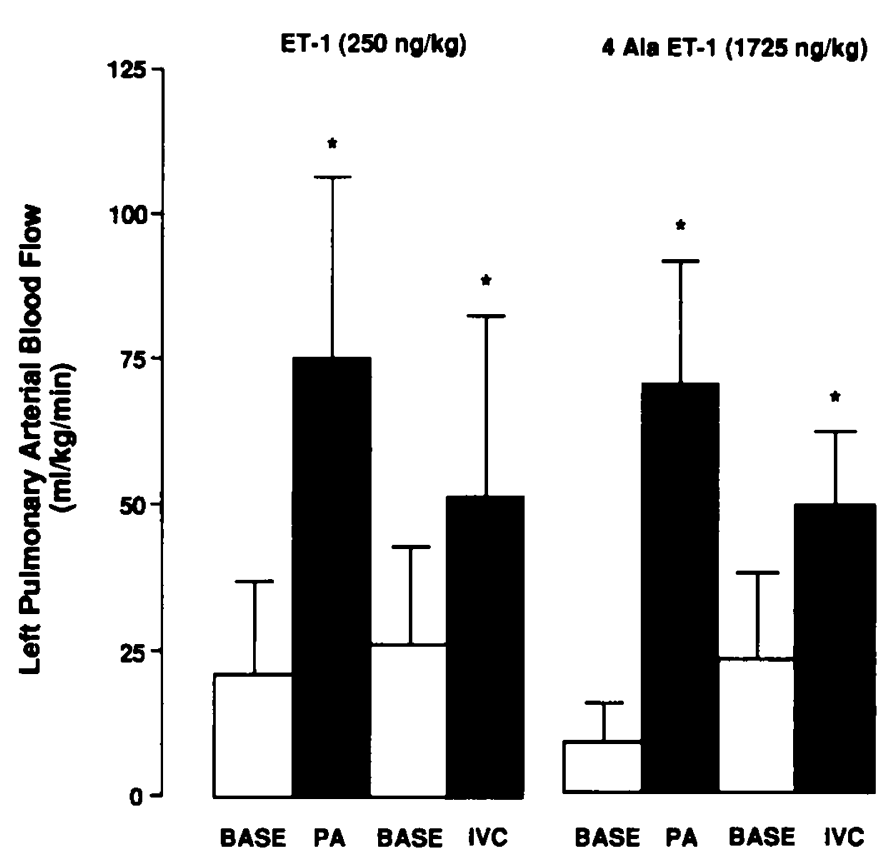

Fig. 1. Injections of ET-1 $(250 \mathrm{ng} / \mathrm{kg})$ or 4 Ala ET-1 $(1725 \mathrm{ng} / \mathrm{kg})$ into the left pulmonary artery $(P A)$ or inferior vena cava $(I V C)$ increase left pulmonary arterial blood flow from baseline $(B A S E)$ in fetal sheep. Values are mean $\pm \mathrm{SD} ; n=6{ }^{*}, p<0.05$ vs previous baseline.

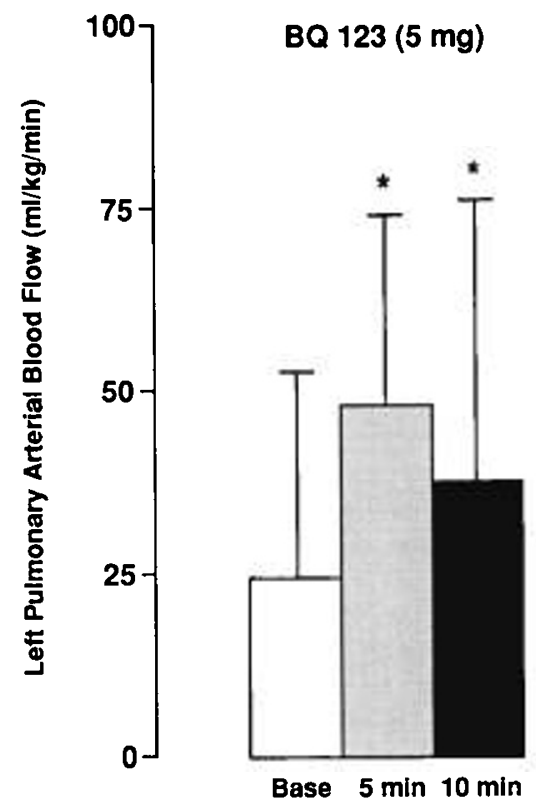

Fig. 2. Infusions of BQ $123(5 \mathrm{mg})$ into the left pulmonary artery increase left pulmonary arterial blood flow at 5 and $10 \mathrm{~min}$. Values are mean $\pm \mathrm{SD} ; n=6 .^{*}, p<0.05$ vs previous baseline.

unchanged. The animals were allowed to rest and the hemodynamic variables returned to baseline levels before an infusion of glibenclamide was started (data not shown).

Before the ET-1 or cromakalim injections were repeated, infusion of glibenclamide into the left pulmonary artery for 15 min increased left pulmonary arterial blood flow (from $34.1 \pm$ 50.0 to $58.0 \pm 53.5 \mathrm{~mL} / \mathrm{kg} / \mathrm{min}, p<0.05$ ) and decreased left pulmonary vascular resistance (from $4.88 \pm 5.88$ to $1.60 \pm 1.14$ $\mathrm{mm} \mathrm{Hg} / \mathrm{mL} / \mathrm{kg} / \mathrm{min}, p<0.05$ ) but did not change mean pulmonary arterial blood pressure. The remaining hemodynamic variables did not change, except for systemic arterial $\mathrm{PO}_{2}$, which increased (from $2.21 \pm 0.60$ to $2.64 \pm 0.39 \mathrm{kPa}, p<0.05$ ).

After the infusion of glibenclamide, ET-1 still increased left pulmonary arterial blood flow and decreased left pulmonary vascular resistance (Table 3). Mean pulmonary and systemic arterial blood pressures were unchanged. Although cromakalim also still increased left pulmonary arterial blood flow, left pulmonary vascular resistance and mean pulmonary and systemic arterial blood pressures were unchanged. However, the absolute increase in left pulmonary arterial blood flow produced by both ET- 1 and cromakalim was significantly attenuated after the infusion of glibenclamide (Fig. 3, Table 3). Glibenclamide attenuated the absolute decrease in left pulmonary vascular resistance induced by cromakalim $(p<0.05)$ but not that produced by ET-1.

\section{DISCUSSION}

This study, in chronically instrumented late gestational age fetal sheep in utero, shows that ET-1 is a potent pulmonary vasodilator and that ET receptor activation partly regulates fetal pulmonary vascular tone. Injections of exogenous ET-1 into the left pulmonary artery and inferior vena cava produced potent increases in pulmonary blood flow in the physiologically high pulmonary vascular tone of the fetus. The infusion of $B Q 123$, an $\mathrm{ET}_{\mathrm{a}}$ receptor antagonist, produced modest increases in left pulmonary blood flow, and the injection of 4 Ala ET-1, an ET receptor agonist, produced potent pulmonary vasodilation. Glibenclamide, an ATP-dependent potassium channel blocker, attenuated the pulmonary vasodilation produced by ET-1, suggesting that this effect is partly mediated by ATP-dependent potassium channels. Although the effects of exogenous ET-1 have been reported previously $(1,2,17)$, the role of endogenous ET-1 in regulating fetal pulmonary vascular tone has not been addressed. Similarly, the role of endothelin receptor subtypes in the regulation of fetal pulmonary vascular tone has not been reported previously.

Using a preparation that completely removes any artifactual changes in pulmonary blood flow caused by ductus arteriosus constriction, this study confirms previous observations that show ET-1 is a pulmonary vasodilator in the fetus $(1,2,17)$. In our study, injections of ET-1 into both the left pulmonary artery and the inferior vena cava increased left pulmonary blood flow. However, injections of ET-1 into the left pulmonary artery produced a greater increase than injections into the inferior vena cava. There are several possible explanations for this difference. One is that the injection of ET-1 into the inferior vena cava is diluted before it reaches the pulmonary circulation so that the effective concentration is less than that of an injection into the left pulmonary artery. Another explanation is that some of the ET-1 from the injection into the inferior vena cava is diverted into the systemic circulation through either the foramen ovale, the ductus arteriosus, or both.

In contrast to the present study, a previous study in sheep of similar gestational ages (124-142 d) showed that infusions of ET1 into the vena cava increased pulmonary arterial pressure and pulmonary vascular resistance (2). Likely explanations for these differences include the dosage used, the method of administration, and, more importantly, the status of the ductus arteriosus, as indicated above. Recent in vitro data suggest that ET-1 is a potent constrictor of the ductus arteriosus $(20,21)$. Therefore, acute constriction of the ductus arteriosus in response to ET-1 may contribute to the increase in pulmonary vascular resistance, as has been described previously in studies that have produced ductus arteriosus constriction by different means $(22,23)$. In our study, injection of ET-1 into the inferior vena cava increased mean pulmonary and systemic arterial blood pressure and calculated left pulmonary vascular resistance in one animal; this may have reflected incomplete formalinization of the ductus arteriosus in that particular fetus. Although not apparent, differences in basal pulmonary vascular tone might also partly explain the different results.

From this study we conclude that the vasoconstricting effects 
WONG ET $A L$.

Table 2. Hemodynamic effects of infusions of $B Q 123$ into the left pulmonary artery in six fetal sheep in utero*

\begin{tabular}{|c|c|c|c|c|c|c|}
\hline & Baseline & BQ $123(5 \mathrm{~min})$ & BQ $123(10 \mathrm{~min})$ & Baseline & $\mathrm{NaHCO}_{3}(5 \mathrm{~min})$ & $\mathrm{NaHCO}_{3}(10 \mathrm{~min})$ \\
\hline $\begin{array}{l}\text { Pulmonary arterial pres- } \\
\text { sure }(\mathrm{mm} \mathrm{Hg})\end{array}$ & $53.5 \pm 11.6$ & $54.2 \pm 9.9$ & $52.2 \pm 10.4$ & $49.7 \pm 4.7$ & $54.2 \pm 9.2$ & $52.2 \pm 7.1$ \\
\hline $\begin{array}{l}\text { Left pulmonary arterial } \\
\text { blood flow }(\mathrm{mL} / \mathrm{kg} / \mathrm{min})\end{array}$ & $24.6 \pm 28.7$ & $47.7 \pm 27.4 \dagger$ & $37.1 \pm 39.5 \dagger$ & $31.1 \pm 39.2$ & $41.1 \pm 39.9$ & $24.7 \pm 24.3$ \\
\hline $\begin{array}{l}\text { Left pulmonary vascular } \\
\text { resistance }(\mathrm{mm} \mathrm{Hg} / \mathrm{mL} / \\
\mathrm{kg} / \mathrm{min})\end{array}$ & $8.84 \pm 10.3$ & $1.43 \pm 0.80 \dagger$ & $2.69 \pm 1.95 \dagger$ & $4.27 \pm 3.6$ & $2.96 \pm 3.28$ & $4.8 \pm 3.7$ \\
\hline $\begin{array}{l}\text { Systemic arterial blood } \\
\text { pressure }(\mathrm{mm} \mathrm{Hg})\end{array}$ & $44.8 \pm 7.9$ & $42.7 \pm 9.0$ & $41.8 \pm 8.9$ & $42.7 \pm 6.0$ & $43.3 \pm 6.9$ & $40.8 \pm 5.4$ \\
\hline Heart rate (beats/min) & $172.0 \pm 30.2$ & $176.8 \pm 22.3$ & $172.8 \pm 27.3$ & $174.4 \pm 37.6$ & $177.6 \pm 35.6$ & $178.4 \pm 33.5$ \\
\hline $\begin{array}{l}\text { Left atrial pressure (mm } \\
\mathrm{Hg} \text { ) }\end{array}$ & $2.0 \pm 2.1$ & $1.8 \pm 1.6$ & $2.8 \pm 1.0 \dagger$ & $2.2 \pm 1.8$ & $2.3 \pm 2.1$ & $2.0 \pm 1.9$ \\
\hline $\begin{array}{l}\text { Right atrial pressure (mm } \\
\mathrm{Hg} \text { ) }\end{array}$ & $3.1 \pm 2.3$ & $2.8 \pm 2.3$ & $3.5 \pm 1.9$ & $2.8 \pm 1.8$ & $3.5 \pm 2.3$ & $3.2 \pm 1.9$ \\
\hline $\mathrm{pH}(\mathrm{U})$ & $7.35 \pm 0.04$ & $7.40 \pm 0.02 \dagger$ & & $7.36 \pm 0.07$ & $7.33 \pm 0.06$ & \\
\hline $\mathrm{PCO}_{2}(\mathrm{kPa})$ & $7.09 \pm 0.64$ & $7.64 \pm 1.28$ & & $7.55 \pm 0.84$ & $7.68 \pm 0.87$ & \\
\hline $\mathrm{PO}_{2}(\mathrm{kPa})$ & $2.36 \pm 0.15$ & $2.28 \pm 0.32$ & & $2.09 \pm 0.37$ & $2.19 \pm 0.32$ & \\
\hline
\end{tabular}

* Data are mean \pm SD for six fetal sheep.

$\dagger p<0.05$ vs previous baseline.

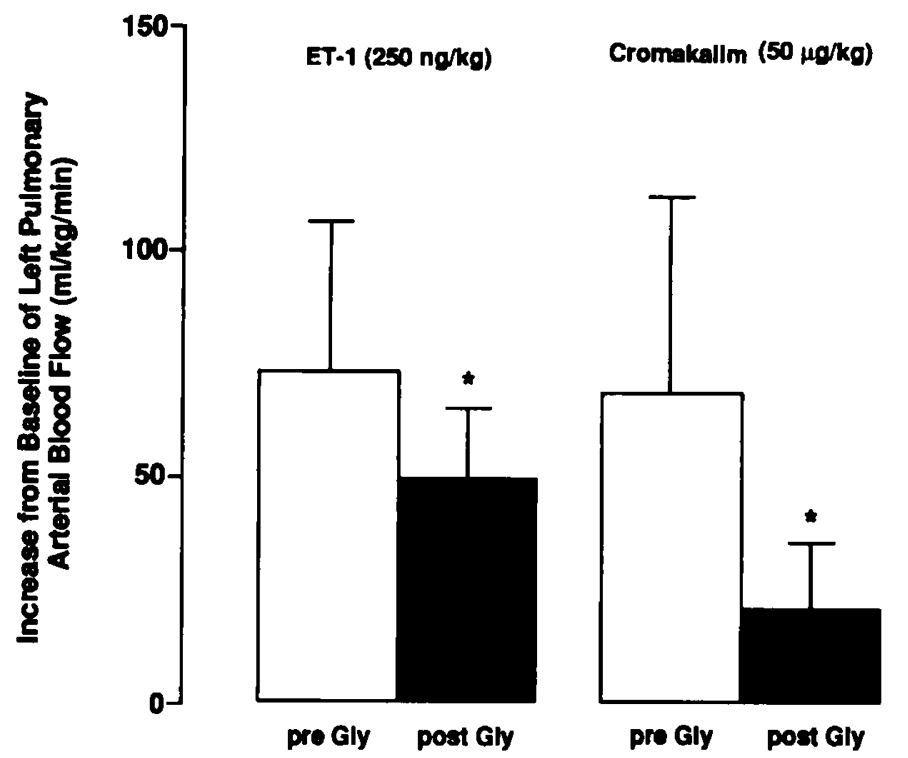

Fig. 3. Infusions of glibenclamide $(G l y)$ into the left pulmonary artery attenuate the absolute increase in left pulmonary arterial blood flow produced by injections of ET-1 $(250 \mathrm{ng} / \mathrm{kg})$ or cromakalim $(50 \mu \mathrm{g} / \mathrm{kg})$ into the left pulmonary artery. Values are mean $\pm \mathrm{SD} ; n=5$. $^{*}, p<0.05$ vs previous baseline.

of ET-1, mediated by $\mathrm{ET}_{\mathrm{a}}$ receptors, contribute to the physiologically high pulmonary vascular tone of the fetus. We have previously shown in newborn lambs that $B Q 123$ is a selective inhibitor of ET-1-induced pulmonary vasoconstriction and does not alter ET-1-induced pulmonary vasodilation (8). BQ 123 has also been shown to inhibit ET-1-induced pulmonary vasoconstriction in isolated adult rat lungs and main pulmonary artery rings (6). The infusion of BQ 123 into the left pulmonary artery in this study produced only a small increase in left pulmonary arterial blood flow and a small decrease in left pulmonary vascular resistance. The modest effect of $B Q 123$ on the pulmonary vascular tone is also transient, inasmuch as the effects rapidly decreased within $10 \mathrm{~min}$. One can speculate that there are relatively few $\mathrm{ET}_{\mathrm{a}}$ receptors in the fetal pulmonary circulation or that either receptor or postreceptor mechanisms that mediate the effects of ET-l are immature. This would be consistent with our earlier observations that a very large dose of ET-1 is required to activate $\mathrm{ET}_{\mathrm{a}}$ receptors to increase resting pulmonary vascular tone in newborn lambs $(4,8)$.
Activation of $\mathrm{ET}_{\mathrm{b}}$ vasodilator receptors by 4 Ala ET-1, a selective $\mathrm{ET}_{\mathrm{b}}$ agonist, produced potent pulmonary vasodilation. The $\mathrm{ET}_{\mathrm{b}}$ agonists are linear polypeptide analogs of the native ET-1 polypeptide. There is an Ala substitution at the $1,3,11$, and 15 amino acid sequence of the native ET-1 polypeptide in 4 Ala ET-1 $(10,11)$. We have previously shown in newborn lambs that 4 Ala ET-1 is a selective pulmonary ET $_{b}$ vasodilator agonist during pulmonary hypertension (18). In this study, the marked decrease in pulmonary vascular tone produced by 4 Ala ET-1 would suggest that the majority of the ET-1 receptors that are of physiologic importance in the near-term fetal pulmonary circulation are $\mathrm{ET}_{\mathrm{b}}$ vasodilator receptors. One can speculate that if there is an abundance of $\mathrm{ET}_{\mathrm{b}}$ vasodilator receptors in the fetal circulation they may play an important role in the transitional circulation of the newborn and in the normal decrease in pulmonary vascular tone that occurs at birth.

The increase in left pulmonary arterial blood flow produced by ET- 1 in fetuses is mediated partly by ATP-dependent potassium channels. We and others have previously shown in newborn lambs and in other species that ET- 1 and $\mathrm{ET}_{\mathrm{b}}$ agonist-induced pulmonary vasodilation is mediated by the release of EDNO or by activation of ATP-dependent potassium channels $(3,4,15-$ 17). As is true in newborn lambs, the pulmonary vasodilating effects of ET-1 in fetal sheep are mediated by the release of EDNO (17). Because the potassium channel blocker glibenclamide did not completely inhibit the effects of ET-1, we presume that part of the pulmonary vasodilation produced by ET-1 in our study is also mediated by EDNO release. In our study, attenuation of the decrease in left pulmonary vascular resistance produced by ET-1 during the infusion of glibenclamide did not reach statistical significance, because in one fetus the decrease in pulmonary arterial blood pressure, and therefore the calculated vascular resistance, was greater after the glibenclamide infusion. However, we still can assume that ATP-dependent potassium channels, as they do in newborn lambs, play a physiologic role in the pulmonary vasodilation and flow effects of ET-1 in the fetus.

Although there were decreases in pulmonary arterial blood pressure, ET-1 and 4 Ala ET-1 did not markedly change systemic arterial blood pressure. We previously showed that ET-1 increased systemic arterial blood pressure, whereas 4 Ala ET-1 did not change systemic arterial blood pressure in newborn lambs (18). A possible reason why ET-1 did not affect the fetal systemic circulation is that the amount of ET-1 reaching the systemic circulation may have been very small. The small, transient decrease in systemic arterial blood pressure produced by ET-1 may be secondary to blood flow diversion from the ductus 
arteriosus to the pulmonary circulation during pulmonary vasodilation. This is in contrast to the finding that infusions of ET1 into the inferior vena cava increased systemic arterial blood pressure (2). The difference may be that the cumulative dose of ET-1 was greater in that study than in our study, and therefore ET- 1 is able to cause systemic vasoconstriction.

In summary, ET-1 and its receptors affect basal fetal pulmonary vascular tone, and both vasoconstrictor and vasodilator receptor subtypes and their mechanisms for producing an effect are present in late-gestation fetal lambs. $E_{a}$ receptors, which mediate ET-1-induced vasoconstriction, contribute a small part to maintaining the high fetal pulmonary vascular tone. However, ET-1, through the activation of $\mathrm{ET}_{\mathrm{b}}$ receptors, markedly decreases fetal pulmonary vascular tone. In healthy newborns, circulating concentrations of ET-1 are higher than in adults (24). From our study and from previous studies, it seems that the role of ET-1 in the perinatal period is to produce pulmonary vasodilation of the transitional circulation through secondary mechanisms such as EDNO production or ATP-dependent potassium channel activation. Aberrations of ET-1 receptors in utero may play a role in the development of pulmonary hypertensive disorders in infancy. Additional studies on the role of ET-1 and its receptors in the normal and abnormal transitional circulation may provide potential new therapies for disorders such as persistent pulmonary hypertension of the neonate.

Acknowledgments. The authors thank Annette M. Doherty, Ph.D., of Parke-Davis, Ann Arbor, MI, for generously supplying 4 Ala ET-1. The authors also thank Scott J. Soifer, M.D., for his assistance and advice, and Roger Chang, Christine Roman, and Mario Trujillo for their technical assistance.

\section{REFERENCES}

1. Cassin S, Kristova V, Davis T, Kadowitz P, Gause G 1991 Tone-dependent responses to endothelin in the isolated perfused fetal sheep pulmonary circulation in situ. J Appl Physiol 70:1228-1234

2. Chatfield BA. McMurtry IF, Hall SL, Abman SH 1991 Hemodynamic effects of endothelin-1 on ovine fetal pulmonary circulation. Am J Physiol 261:R182-R187

3. Perreault T, De Marte J 1991 Endothelin-1 has a dilator effect on neonatal pig pulmonary vasculature. J Cardiovasc Pharmacol 18:43-50

4. Wong J, Vanderford PA, Fineman JR, Chang R. Soifer SJ 1992 Endothelin-1 produces pulmonary vasodilation in the intact newborn lamb. Am J Physiol 265:H1318-H1325

5. Bazil MK, Lappe RW, Webb RL 1992 Pharmacologic characterization of an endothelin a $\left(E T_{2}\right)$ receptor antagonist in conscious rats. J Cardiovasc Pharmacol 20:940-948

6. Bonvallet ST, Oka M, Yano M, McMurtry IF, Stelzne TJ 1993 An endothelin receptor antagonist attenuates endothelin-1 (ET-1) induced vasoconstriction in the rat pulmonary circulation. J Cardiovasc Pharmacol 22:39-43

7. Ihara M, Noguchi K, Saeki T, Fukuroda T. Tsuchida S, Kimura S. Fukami T, Ishikawa K. Nishikibe M. Yano M 1991 Biological profiles of highly potent novel endothelin antagonists selective for the $\mathrm{ET}_{\mathrm{a}}$ receptor. Life Sci 50: 247-255

8. Wong J, Vanderford PA, Winters JW, Chang R, Soifer SJ, Fineman JR 1993 Endothelin- 1 does not mediate acute hypoxic pulmonary vasoconstriction in intact newborn lambs. J Cardiovasc Pharmacol 22:S262-S266

9. Moreland S, McMullen DM. Delaney CL. Lee VG. Hunt JT 1992 Venous smooth muscle contains vasoconstrictor $\mathrm{ET}_{\mathrm{b}}$-like receptors. Biochem Biophys Res Commun 184:100-106

10. Panek RL, Major TC. Hingorani GP, Doherty AM, Taylor DG, Rapundalo ST 1992 Endothelin and structurally related analogs distinguish between endothelin receptors subtypes. Biochem Biophys Res Commun 183: $566-571$

11. Saeki T. Ihara M, Fukuroda T, Yamagiwa M, Yano M 1991 (Ala1,3,11.15) Endothelin-1 analogs with $\mathrm{ET}_{\mathrm{b}}$ agonistic activity. Biochem Biophys Res Commun 179:286-292

12. Shetty SS, Toshikazu O, Webb RL. DelGrande D, Lapp RW 1993 Functionally distinct Endothelin b receptors in vascular endothelium and smooth muscle. Biochem Biophys Res Commun 191:459-464

13. Sokolovsky M, Ambar I, Galron R 1992 A novel subtype of endothelin receptors. J Biol Chem 267:20551-20554

14. Sokolovsky M 1992 Endothelins and larafotoxins: physiological regulation receptor subtypes and transmembrane signaling. Pharmacol Ther 54: 129-149

15. Hasunuma K, Rodman DM, O'Brien RF, McMurtry IF 1990 Endothelincauses pulmonary vasodilation in rats. Am J Physiol 259:H48-H54

16. Lippton HL, Cohen GA, McMurtry IF, Hyman AL 1991 Pulmonary vasodi- 
lation to endothelin isopeptides in vivo is mediated by potassium channel activation. J Appl Physiol 70:947-952

17. Tod ML, Cassin S 1992 Endothelin-1 induced pulmonary arterial dilation is reduced by $\mathrm{N}^{\mathrm{w}}$-nitro-L-arginine in fetal lambs. J Appl Physiol 72:1730-1734

18. Wong J, Winters JW, Vanderford PA, Fineman JR, Soifer SJ 1993 ET $_{b}$ receptor agonists produce potent pulmonary vasodilation in the intact newborn lamb. Pediatr Res 33:71A(abstr)

19. Chang J-K, Moore P, Fineman JR, Soifer SJ, Heymann MA $1992 \mathrm{~K}^{+}$channel pulmonary vasodilatation in fetal lambs: role of endothelial derived nitric oxide. J Appl Physiol 73:188-194

20. Coceani F, Armstrong C, Kelsey L 1989 Endothelin is a potent constrictor of the lamb ductus arteriosus. Can J Physiol Pharmacol 67:902-904
21. Coceani F. Kelsey L, Seidlitz E 1992 Evidence for an effector role of endothelin in closure of the ductus arteriosus at birth. Can J Physiol Pharmacol 70:10611064

22. Abman SH, Accurso FJ 1989 Acute effects of partial compression of ductus arteriosus on fetal pulmonary circulation. Am J Physiol 257:H626-H634

23. Heymann MA, Rudolph AM 1976 Effects of acetylsalicylic acid on the ductus arteriosus and circulation in fetal lambs in utero. Circ Res 38:418-422

24. Yoshibayashi M, Nishioka K, Nakao K. Saito Y, Temma S, Matsumura M, Ueda T, Shirakami G, Imura H, Mikawa H 1991 Plasma endothelin levels in healthy children: high values in early infancy. J Cardiovasc Pharmacol 17(suppl 7):S404-S405

\section{Announcement}

\section{Ares Serono International Symposium}

The Ares Serono International Symposium, "Where Phenotype Does Not Match Genotype," will be held in the Cassa di Risparmio in Volterra, Italy, from October 13 to 14, 1994. For further information, contact Maria I. New, M.D., Scientific Secretary, The New York Hospital-Cornell Medical Center, 525 E. 68th Street, Room N236, New York, NY 10021, phone (212) 746-3450, fax (212) 746-0300. A limited number of free communications will be accepted for poster presentation. Abstracts must be sent to Maria I. New, M.D., postmarked no later than June 15, 1994. 